\title{
GENETIC STUDIES OF THE SYRIAN HAMSTER. X. REX
}

\author{
ROY ROBINSON \\ St Stephen's Road Nursery, Ealing, London W13
}

Received 25.vii.75

\section{SUMmary}

The rex mutant has its most obvious effect on coat structure but it also reduces 21-day body weight by about 14 per cent. There is no apparent effect on viability nor on the fecundity of the more robust rex females. Extensive tests for linkage with the genes $b, B a, c^{d}, D s, e, l, L g, r u, S a$ and $W h$ have proved to be negative. A less extensive test with $s$ was also negative.

\section{INTRODUCTION}

REX ( $r x$; Whitney and Nixon, 1973) is one of the three known mutant genes which modify coat structure in the Syrian hamster (Mesocricetus auratus). The others are satin (Sa; Robinson, 1972) and long hair ( $l$; Schimke, et al., 1973). This paper describes some interesting phenotypic interactions between these genes and the results of tests for linkage with eleven mutant genes.

\section{The ReX PHENOTYPE}

The rex has characteristically curly vibrissae, classifiable at birth, which tend to curve inwards towards the nose, to give a "walrus" effect. The coat is short and generally feels soft and plush-like but, on the other hand, it may feel slightly crinkled. All of the hair types appear to be present in the rex coat by microscopic inspection but are shorter than normal and are exaggeratedly undulated. The normal straight and overlapping guard hairs are reduced in length to about that of the underfur.

A small number of rex have a thin coat throughout their life, where the skin can easily be seen. A higher proportion of animals have a thin juvenile coat but a good covering of hair as adults. In all animals with a sparse coat, the stomach is noticeably less well covered than the dorsum. This variation probably parallels the situation in the normal coated animal but is more apparent.

The young rex shows marcel waving which is most obvious between the ages of two to three weeks. This is a feature which the mutant shares with the waved genes of the house mouse ( $c f$. Carter, 1951). The marcel waving is enhanced in animals of genotypes $l l r x r x, \operatorname{rxr} x S a+$ and $l l r x r x S a+$, the amount of waving being somewhat more pronounced for each genotype from left to right. In all cases the waving disappears after about 3 weeks of age. The coat of $l l r x r x$ animals is shorter, softer and more inclined to matt than that of ordinary long hair $(l l)$. The satin sheen of $S a+$ is fully apparent in both $r x r x S a+$ and $l l r x r x S a+$ individuals. The hairs of $S a$ heterozygotes are thinner than normal and a much higher proportion of $r x x x S a+$ animals have an obviously thin coat. The coat of $l l r x r x S a+$ animals are correspondingly fine in texture. 


\section{BODY WEIGHT AND LITTER SIZE}

Early in these studies it was observed that, while the majority of rex were as large as normal hamsters, a proportion were decidedly smaller. These smaller individuals were often those with the thinner coats, as if the rex gene had a general retarding effect on development. Accordingly, young animals of weaning age (21 days) were routinely weighed. Only litters of between four to seven young were examined to minimise the influence of litter size. The opportunity was taken to include the long-haired gene in the analysis because the gene was assorting in the form of backcrosses of diheterozygotes $(+l+r x \times l l r x r x)$, so that the mutants had a common genetic background.

The results of the weight analysis are summarised in tables 1 and 2.

TABLE 1

Mean body weight at 21 days of age and mean litter size for combinations of the mutant genes rex and long-hair of the hamster

\begin{tabular}{lccccccc} 
& \multicolumn{4}{c}{ Weight $(\mathrm{g})$} & & \multicolumn{2}{c}{ Litter size } \\
\cline { 2 - 5 } $\begin{array}{l}\text { No. } \\
\text { Phenotype }\end{array}$ & Nean & G.V. & Range & & No. & Mean \\
Normal & 88 & $36 \cdot 1 \pm 0 \cdot 5$ & $13 \cdot 4$ & $28-44$ & & 190 & $8 \cdot 0 \pm 0.2$ \\
Long-hair & 58 & $35 \cdot 6 \pm 0 \cdot 5$ & $10 \cdot 2$ & $29-42$ & & 87 & $8 \cdot 5 \pm 0.3$ \\
Rex & 79 & $31 \cdot 1 \pm 0 \cdot 2$ & $11 \cdot 8$ & $23-42$ & & 50 & $8 \cdot 3 \pm 0.4$ \\
Rex long-hair & 56 & $30 \cdot 3 \pm 0.5$ & $12 \cdot 1$ & $23-38$ & & 42 & $7 \cdot 9 \pm 0.2$
\end{tabular}

TABLE 2

Two-way analysis of variance for body weight at 21 days of rex and long-haired hamsters

$\begin{array}{lrrrc}\quad \text { Item } & \text { S.S. } & \text { d.f. } & \text { M.S. } & F \\ \text { Rex } & 1827 & 1 & 1827 & 107 \cdot 47 * \\ \text { Long-hair } & 38 & 1 & 38 & 2 \cdot 24 \\ \text { Interaction } & 20 & 1 & 20 & 1 \cdot 18 \\ \text { Error } & 4621 & 277 & 17 & - \\ \quad \text { Total } & 6506 & 280 & & \\ & \text { * Highly significant }\end{array}$

The rex mutant significantly reduces body size while long-hair does not. The range of variation reveals that the smallest of the rex animals weighed about 82 per cent of the smallest of the normals. It is interesting that the small animals are usually lively and not overtly emaciated. At the other end of the scale, the largest of the rexes are not undersized at 21 days and mature into adults which are comparable to normal in all respects. The males are sexually active and the mothers display normal fertility, fecundity and maternal care.

Despite the significant difference of body weight between the rex versus normal and long-haired animals, little differences are apparent for mean litter size. The overall mean for 369 litters from the four types of female was $8.2 \pm 0.1$ young for 369 litters. The range of litter sizes was 2 to 17 young, with 95 per cent of litters falling within the range of 4 to 13 . Table 1 shows that the mean litter sizes for each type of female scarcely differs from the 
overall mean. It may be anticipated that the rex females would have smaller litters because Robens (1968) has tabulated data which shows that mean litter size is influenced by weight. However, in these experiments, only the larger females were chosen for breeding; hence the weight factor was neutralised and there is no indication that either the rex or long-haired mutant genes per se have an effect on litter size.

It may be wondered if the impaired growth may have an effect on viability. There is indeed a small deficiency of rex animals for both the testcrosses and intercrosses but this is insignificant. Over the various samples of 1025 testcross young (529 normal:496 rex) and 1900 intercross young (1442 normal: $458 \mathrm{rex}$ ), the viability of rex is 97 per cent of normal. The $\chi^{2}$ calculated on the observed number of rex versus the number expected with no viability disturbance is $1 \cdot 1$ ( 1 d.f.), which is not significant.

\section{Tests FOR LINKAgE}

Rex has been tested for possible autosomal linkage with eleven mutant genes: brown $(b)$, white band $(B a)$, acromelanic albinism $\left(c^{d}\right)$, dominant spot $(D s)$, non-extension of eumelanism $(e)$, long hair $(l)$, lethal grey $(L g)$, ruby-eye $(r u)$, piebald $(s)$, satin $(S a)$ and anophthalmic white $(W h)$. Full descriptions of these mutants may be found in Nixon, et al. (1970) and Robinson (1975). All of the tests, with the exception of that with $s$, are adequate to exclude any but very loose linkage (greater than 40 to 45 per cent crossingover).

The only crosses to have minor complications were those involving the $r u$ and $s$ genes. Both of these confer lower viability on animals homozygous for them. The estimated viability for $r u$ at 21 days of age is $0 \cdot 651 \pm 0.078$.

TABle 3

Summary of linkage tests undertaken with rex and estimated recombination percentages

\begin{tabular}{|c|c|c|c|c|c|c|}
\hline \multirow[b]{2}{*}{ Gene } & \multirow[b]{2}{*}{$\begin{array}{l}\text { Mating } \\
\text { type }\end{array}$} & \multicolumn{4}{|c|}{ Phenotype } & \multirow[b]{2}{*}{$\begin{array}{c}\text { Recombination } \\
\text { percentage }\end{array}$} \\
\hline & & $+X$ & $r x X$ & ++ & $r x+$ & \\
\hline$B a$ & CBB & 229 & 198 & 230 & 218 & $48.9 \pm 1.7$ \\
\hline Ds & CBB & 157 & 164 & 181 & 143 & $53.5 \pm 2 \cdot 0$ \\
\hline$L g$ & CBB & 163 & 154 & 175 & 153 & $50 \cdot 0 \pm 2 \cdot 0$ \\
\hline $\mathrm{Sa}$ & CBB & 222 & 220 & 231 & 196 & $52.2 \pm 1.7$ \\
\hline \multirow[t]{2}{*}{$W h$} & CBB & 164 & 146 & 175 & 182 & $48.1 \pm 1.9$ \\
\hline & CIB & 72 & 82 & 24 & 27 & $50 \cdot 7 \pm 6 \cdot 0$ \\
\hline \multirow[t]{2}{*}{ Mean } & & & & & & $50.4 \pm 1.6$ \\
\hline & & ++ & $r x+$ & $+x$ & $r x X$ & \\
\hline$b$ & CII & 251 & 76 & 71 & 20 & $49 \cdot 3 \pm 3 \cdot 7$ \\
\hline$c^{d}$ & CII & 251 & 74 & 71 & 22 & $51 \cdot 0 \pm 3 \cdot 6$ \\
\hline 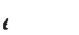 & CII & 201 & 55 & 52 & 20 & $55 \cdot 1 \pm 3.9$ \\
\hline$l$ & CII & 412 & 135 & 120 & 53 & $54 \cdot 1 \pm 2 \cdot 7$ \\
\hline$r u$ & CII & 293 & 99 & 64 & 21 & $49.6 \pm 3.9$ \\
\hline$s$ & CII & 54 & 16 & 6 & 2 & $53 \cdot 1 \pm 10 \cdot 4$ \\
\hline
\end{tabular}

$X$ and $x$ represent the dominant or recessive gene, respectively, of the first column. $\mathrm{C}=$ coupling, $\mathrm{B}=$ backcross and $\mathrm{I}=$ intercross of the respective genes in the notation of Robinson (1971b). 
This compares with estimates ranging from 0.546 to 0.691 from crosses with different stocks (Robinson, 1971 a). The estimated viability for $s$ at 21 days of age is $0.343 \pm 0 \cdot 128$. This compares with estimates of 0.367 and 0.381 from crosses reported previously (Robinson, 1971a). The level of viability associated with $r u$ and $s$ in the present crosses is in no way extraordinary and has been allowed for in the computation of the standard errors.

The closest linkage which would be compatible with the observed assortment data has been calculated by multiplying the standard error by 1.96 and subtracting the product from the estimated recombination fraction. The results for tests with the respective genes are: $B a 46 \cdot 0$, $D s$ 49.6, $L g$ 47.2, $S a 48 \cdot 9$, Wh $47 \cdot 3, b 42 \cdot 0, c^{d} 43 \cdot 8, e 47 \cdot 4, l 48 \cdot 9$, ru $42 \cdot 0$ and $s 32 \cdot 8$ per cent.

\section{Discussion}

It is patent that rex of the Syrian hamster belongs to the general category of rexoid coat mutants. These genes are numerous both within and between species. That most thoroughly investigated laboratory mammal, the house mouse, has some eight different loci giving rise to rexoid alleles. The occurrence of rex mutants is not confined to rodents (mouse, cavy, rat) but is known for lagomorphs (rabbit), carnivores (cat, dog, mink, silver fox) and ungulates (horse, pig). Recessive heredity appears to be the rule for these mutants but a few are dominant (mouse, rat).

It is impossible to homologise rex of the Syrian hamster to specific rexoid mutants of other species until the modes of action of the various genes have been studied in detail. Tentatively, the hamster mutant may be compared with waved-1 (wa-1) or waved-2 (wa-2) of the mouse. The phenotypic resemblance and recessive inheritance would point in this direction. It is clear that the rex coat represents a distinctive genetic anomaly of hair development which transcends species. This fact, coupled with the variety of mutants now available for study, should commend itself to the attention of those interested in the physiology of mammalian hair.

Acknowledgment.- - I am indebted to Dr C. William Nixon for the gift of rex animals which enabled this work to be performed.

\section{REFERENGES}

GARTER, T. G. 1951. Wavy coated mice: phenotypic interactions and linkage tests between rex and waved and waved-2. 7. Genet., 50, 268-276.

NIXON, G. W., BEAUMONT, J. H., AND CONNELLY, M. E. 1970. Gene interaction of coat patterns and colors in the Syrian hamster. J. Hered., 61, 221-228.

ROBENS, J. F. 1968. Influence of maternal weight on pregnancy, number of corpora lutea, and implantation sites in the golden hamster. Lab. Anim. Care, 18, 651-653.

RoBINSON, R. 1971a. Genetic studies of the Syrian hamster. VII. Independence data. Heredity, 26, 65-71.

Robinson, R. 1971b. Gene Mapping in Laboratory Mammals. Part $A$. The Biometrical Approach. Plenum Press, London.

Robinson, R. 1972. Satin-a new coat mutant in the Syrian hamster. 7. Hered., 63, 52. robinson, R. 1975. The Syrian hamster. In Handbook of Genetics, ed. R. C. King, vol. 4. Plenum Press, London.

SCHIMKE, D. J., NIXON, C. W., AND CONNELLY, M. E. 1973. Long-hair: a new mutation in the Syrian hamster. J. Hered., 64, 236-237.

WHITNEY, R., AND NIXON, c. w. 1973. Rex coat: a new mutation in the Syrian hamster. J. Hered., 64, 239. 